\title{
Clusters - the basis of competition
}

\author{
A. S. Carrie \\ Department of Design, Manufacture and Engineering \\ Management, University of Strathclyde \\ 75 Montrose Street, Glasgow, G1 1XJ, Scotland, UK \\ Tel: $+44(0) 1415482894$ \\ Fax: +44 (0) 1415520557 \\ e-mail:a.s.carrie@strath.ac.uk
}

\begin{abstract}
As manufacturing becomes a truly global affair, the basis of competition will no longer be between individual companies and their supply chains but between regional industrial clusters. Large multi-nationals can relocate operations to any part of the world, with significant impact on the regions into and out of which they move. This has significant implications for economic development in any regional economy. This paper discusses the nature of clusters, giving some examples. Nevertheless, the cluster concept is only partially understood. Many questions concerning cluster development need to be examined. The paper presents a research agenda.
\end{abstract}

\section{Keywords}

Industry clusters, economic development, regional economies, research agenda

\section{INTRODUCTION}

In the 1960s and 70s, competition was between companies. In those days companies tended to make most of their components and assemble their products themselves. They were integrated enterprises. In the 80 s and 90 s companies outsourced a much larger part of their components and assemblies, and became extended enterprises. Competition was between supply chains. Supply chain management became a major management skill.

In the 2000s, as competition becomes a global factor, competition will be between clusters of inter-related organisations that create value through cooperation. The name "Silicon Valley" testifies to the existence of an electronics cluster in California. Large multi-nationals can relocate operations to any part of the world, which can have significant impact on the regions into and out of which 
they move. The competitiveness of industry in any region of the world will depend much more on its total business infrastructure, which will attract companies to, and retain them in, any region of the world.

The cluster concept goes far beyond the supply chain concept, which focuses on an organisation and its customers and suppliers. Managers need to re-examine their assumptions about competitive strategy. In particular, they must recognise the inter-dependence of all the stakeholders in the economic infrastructure of their region of the world.

\section{THE NATURE OF CLUSTERS}

A cluster is a network of companies, their customers and suppliers of all the relevant factors, including materials and components, equipment, training, finance and so on. It extends to educational establishments and research institutes who provide a large part of their human and technological capital. They are all stakeholders in the end market, influenced by globalisation, commercialisation, skills development, inward investment, start-ups and trade development. For example, a clothing manufacture cluster might include:

- Farms which produce the natural materials, such as wool and cotton

- Spinners, mills, dyers and cloth manufacturers

- Textile engineers, fashion designers and fashion show organisers who set the trends in terms of touch and feel of the materials, colours, cuts, styles, etc.

- The transportation, warehousing and distribution providers

- High street stores, licensees, franchisees, and so on

- End users, who buy the garment, use it and dispose of it

- Public bodies, service providers, universities, colleges and professional advisors

- Research institutes exploring better design and production processes and computer systems.

The international working conference on Strategic Management of the Manufacturing Value Chain, in August 1998 (Bititci and Carrie, 1998) concluded that:

- In the new millennium, competition will be between clusters of companies, customers, suppliers and other private and public stakeholders (as illustrated above) rather than between individual companies.

- Emerging information technologies (such as Internet, Intranet, and Workflow Systems) will provide the technological infrastructure that will facilitate the integration of various organisations into an effective and efficient cluster.

- Research, taking an integrated, systems approach should be undertaken to create a managerial knowledge base for efficient and effective management of integrated cluster systems.

In recent years, there has been much discussion of extended and virtual organisations. The cluster concept extends and transcends this discussion. The entire cluster is a form of virtual enterprise. Frequently, some component of a 
cluster will serve several industries and can be a member of several clusters. For example, companies in the display technology business may be part of an electronics cluster, a defence cluster and an entertainment cluster.

\section{THE THEORETICAL BASIS OF THE CLUSTER CONCEPT}

The theoretical basis of the cluster concept, as a factor in competitive advantage, was put forward by Porter (Porter, 1980). He argued that the strength of a cluster depends on several interacting factors, which can be grouped under four headings (Figure 1):

- Firm strategy, structure and rivalry

- Demand conditions

- Related and supporting industries

- Factor conditions.

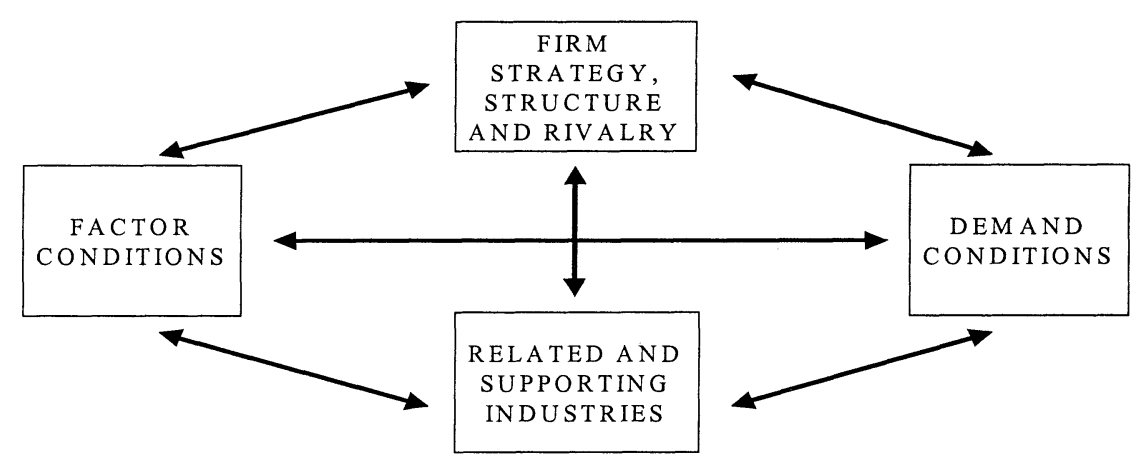

Figure 1 Cluster Factors Diamond (Porter 1980).

Three of these are somewhat self-explanatory. Factor Conditions relate to climate, labour supply and skills availability, presence and strength of research establishments, taxes, government incentives, wage levels, cost of living and so on. The interplay of all these factors (indicated by the arrows) promotes or hinders business success and economic development in any region.

For example, in the electronics cluster in Austin, Texas, these factors are represented by:

Firm strategy, structure and rivalry: there are some 400 companies and the largest concentration of software and semiconductors in America

Demand conditions: there is a strong local base of technologically sophisticated buyers

Related and supporting industries: a fast-growing venture capital network, strong research base and upstream suppliers

Factor conditions: above average education system, low taxes, low unionisation, low cost of living and a high quality of life. 
Another way of describing a cluster is to develop a map of interrelated industries. For example, Figure 2 illustrates the Swedish timber products industry.

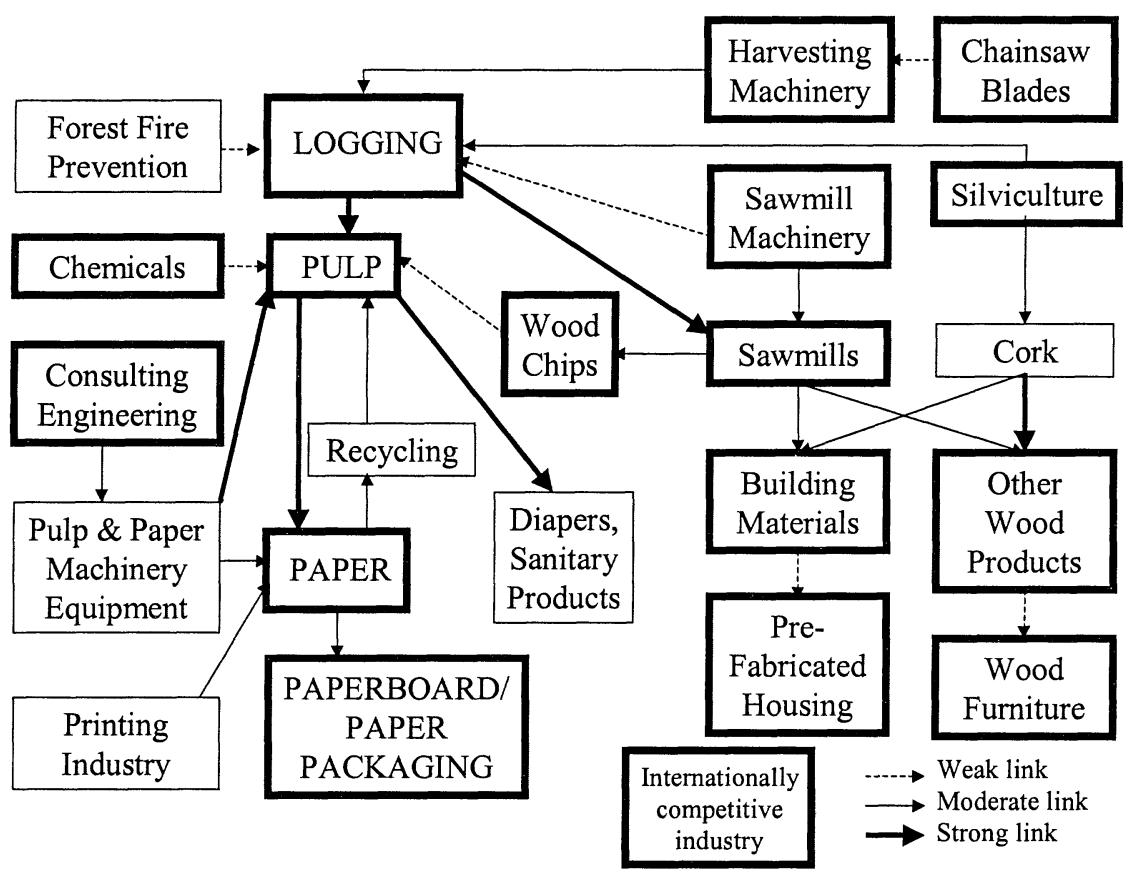

Figure 2 Sweden's timber products industry cluster.

\section{ARIZONA'S CLUSTER APPROACH}

Arizona's State Government has made clusters a central plank of its economic development strategy. The aim is to enable a vital cycle to begin, generating more competitive businesses and creating wealth for the community from new jobs, taxes, purchases, volunteers and contributions. The State Government concentrates on promoting seven "foundations" that create an environment conducive to economic development:

- Human resources

- Capital

- Quality of life

- Technology

- Tax and regulation

- Information and communications infrastructure

- Physical infrastructure. 
Four criteria have been established for identifying clusters and selecting industries that may be eligible for Government support.

- Presence above national average

- Growth rate above national average

- Export orientation

- Interdependence among member firms, including large and small companies, their suppliers and their geographical grouping.

Because of these criteria, nine clusters have been established, although the number is not static. The State Government does not impose any particular way of working on the clusters, instead it gives assistance and encouragement to the players in an industry to get together. The Arizona clusters are led by industrial personnel and are principally a forum for networking among companies with interests in a particular sector of the economy. One outcome is that companies recognise that, although they may be competitors in some aspects of their business, they have many common interests. For example, several small companies have discovered that together they can bid for large contracts that they could not hope to on their own.

\section{SCOTLAND'S APPROACH TO CLUSTER DEVELOPMENT IN A REGIONAL ECONOMY}

In common with other regions, Scotland is having to cope with a legacy of declining traditional industries while building up viable clusters in the industries of tomorrow. A century ago, Scotland had the strongest cluster in the world in the shipbuilding industry, in which the manufacture of steel, pumps, diesel engines, etc. all played a contributory part. The phrase "Clyde-built" became a by-word of dependability. Scottish engineers were to be found on vessels all over the world (A descendant became engineer of the Starship Enterprise).

The electronics industry, which is a very large sector of the Scottish economy, forms one of the modern clusters. Most of the major OEMs are present in Scotland's electronics industry. Almost half of the PCs sold in Europe are assembled here. A substantial support industry has grown up to support the OEMs, including plastic moulders, packaging suppliers, sheet metal companies and a wide range of subcontract assemblers. One of the weaknesses is that so much of our electronics industry is foreign owned. Therefore, these companies could migrate to other regions, such as Eastern Europe, depending on world economics unless embedded into a strong cluster here. An important part of any cluster, is the network of supporting suppliers. In the electronics industry, local suppliers have done well in securing a share of OEMs' purchases. However, as industry becomes more global, more of the sourcing decisions may be made at corporate headquarters. This, and the establishment of supplier hubs in Scotland, may be more difficult for local firms to enlarge or maintain their share of this market (Carrie and Reid, 1998). 
Scottish Enterprise, the body charged with economic development in Scotland has adopted a cluster strategy (Porter, 1998). A recent study found that, of 30 or so identifiable industries, 13 industries were potential clusters, including information industries, multi-media, value-added engineering, chemicals, forest products, financial services, tourism and education services. Scottish Enterprise has established four pilot clusters. These are semiconductors, oil and gas, food and drink and biotechnology. The first three of these are already major sectors of the economy, while the fourth is a fast growing sector. The semiconductor industry has sales of around \$3billion per year, representing about $2 \%$ of the world market. The industry as a whole is strong here, but within this situation, there are weaknesses. For example, although our electronics industry consumes about $\$ 5$ billion of semiconductors annually, virtually none of these chips is made here. Those made here are exported to plants in Europe, America and elsewhere.

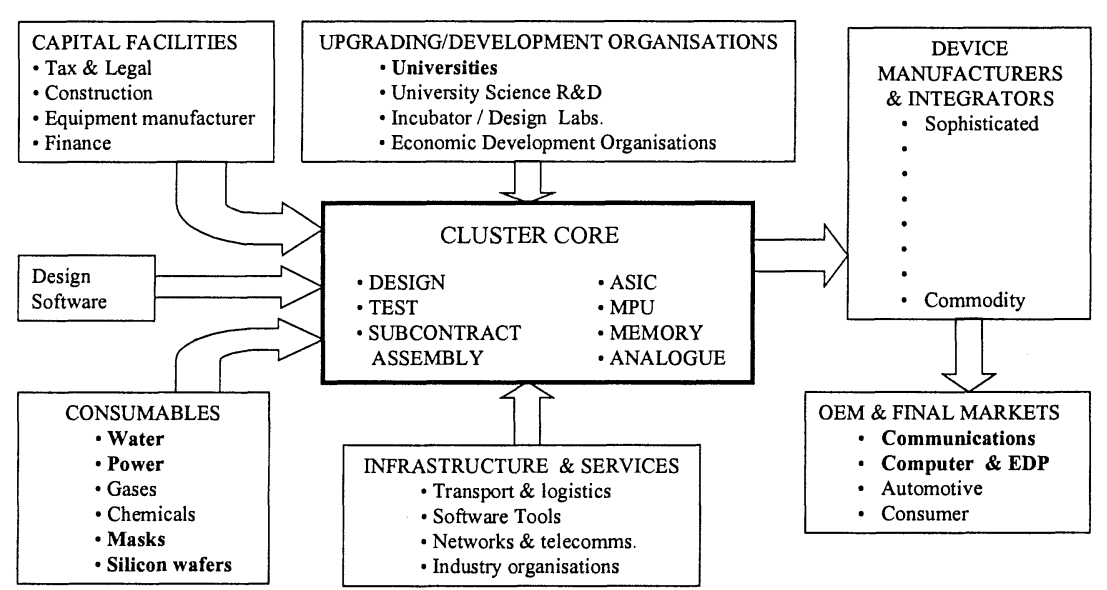

Figure 3 Linkages in Semiconductor cluster.

Among factor conditions influencing economic development, Scotland has many advantages, including good higher education institutions, world class research groups, benign climate, plentiful clean water, good quality of life and a strong sense of cultural identity.

\section{RESEARCH AGENDA}

Although the cluster concept is quite widely recognised, it is still really just a concept. There is a need for research to put flesh onto the concept and establish operating principles and guidelines. A fundamental question is whether a cluster amounts to more than the sum of the member firms. Can a cluster have a life of its own and add value to its member firms? Some of the research questions are: 
- Is there a formal definition of an economic cluster? Can a formal definition be developed which would be robust and widely applicable?

- Are there certain fundamental criteria for the formation or existence of a cluster? For example, are the Arizona criteria widely applicable?

- Are specific environmental conditions necessary for the successful existence of a cluster? These could include market factors, government policies, employment practices and skills, global competition, etc. A recent study concluded that local factor conditions in any region are likely to be a major influence (Carrie, 1999).

- Can clusters be created or do they just emerge as a result of actions of a large number of players? A recent technology management study tour of Arizona (ITM, 1998) concluded that Arizona's successes seem to depend very much on factor conditions, such as climate, over which we can have little influence, and the general buoyancy of the American economy.

- What is the role of governmental agencies in cluster management? The extent to which Governments become directly involved in such matters varies tremendously. In Arizona, the Government adopts a minimal role, seeking to create an entrepreneurial climate through low taxes and low regulation. In other regions, Governments seek to lead the process.

- How are the competitive and collaborative aspects of companies within a cluster to be managed? Is this analogous to a benchmarking club or is it a deeper relationship? Can specific mechanisms be developed to manage competition/collaboration among cluster member firms?

- How should cross-cluster issues be managed, e.g. where a company may be a member of several clusters? Are sub-clusters viable, e.g. a semiconductor subcluster within an electronics cluster?

- Can a cluster have a manufacturing strategy in the way that an individual firm can have a strategy? Can the various models in the literature be applied to clusters? For example, can a cluster as a whole migrate towards the high-value end of the market, or should it maintain coverage of the entire market spectrum?

- Can strategies for establishing a wide set of core competencies among member firms be developed, so that individual firms do not need to possess too wide a range of skills?

- Is there a specific role for the cluster in knowledge management? Are there specific ways in which the members of a cluster can take advantage of IT, www, etc. in a way that goes beyond that which an individual company could pursue?

- How is the performance of a cluster to be measured? How can such measures be deployed to individual firms within the cluster?

No doubt, this list could be enlarged greatly. Some of these issues are fundamental, while others are of secondary importance. 


\section{CONCLUSION}

It has been suggested that in the next decade competition will be between regional clusters rather than individual firms and their supply chains. There is clear evidence of this trend around the world. However, the state of knowledge on the subject appears to be rudimentary. A research agenda has been proposed.

\section{REFERENCES}

Bititci, U.S. and Carrie, A.S. 1998, editors, Strategic Management of the Manufacturing Value Chain, IFIP, Kluwer Academic Publishers, Dordrecht, The Netherlands, ISBN 0-412-82710-7

Carrie, A.S. 1999, Technology management as a global discipline - Some international observations, Proceedings IEEE Engineering Management Society Conference, IEEE, Washington.

Carrie, A.S. and Reid, A.E. 1998, Impact of Supplier Hubs on the Scottish Electronics Industry, Strategic Management of the Manufacturing Value Chain, Edited by Bititci U S and Carrie A S, IFIP, Kluwer Academic Publications, Dordrecht, The Netherlands, pp37-44.

ITM, Strategic Technology Management in Arizona, Institute of Technology Management, Heriot-Watt University, 1998.

Porter, J. 1998, The Role of High Technology in a Regional Economy, Strategic Management of the Manufacturing Value Chain, Edited by Bititci U S and Carrie A S, IFIP, Kluwer Academic Publications, Dordrecht, The Netherlands.

Porter, J. 1980, Competitive Advantage, Free Press, New York.

\section{BIOGRAPHY}

Allan Carrie is Professor of Manufacturing Systems at the Centre for Strategic Manufacturing in the Department of Design, Manufacture and Engineering Management at the University of Strathclyde. He was a member of the Manufacturing Production and Business Processes Panel of the UK Technology Foresight Programme from 1994-97 and Chairman of the Panel's Focus Group on the Electronics Industry. He manages a Master's programme on Technology Management His research interests lie in the field of manufacturing systems and production management. Current or recent projects have dealt with Manufacturing Integration, Performance Measurement Systems and Manufacturing Franchising. $\mathrm{He}$ is the author of a book entitled Simulation of Manufacturing Systems and over 120 papers. 